\title{
Génesis del nóema: un análisis noemático a partir de la constitución del cuerpo adolorido
}

\author{
Genesis of the noema: A noematic analysis based on \\ the constitution of the body in pain
}

\author{
Alejandro Escudero Morales \\ Facultad de Filosofía y Humanidades, Universidad de Chile, Chile \\ a.escudero@live.cl
}

\begin{abstract}
Resumen
El presente trabajo tiene por objetivo la realización de un estudio genético sobre el concepto husserliano de nóema a partir de la dación del cuerpo real en la experiencia pasiva de dolor. El desarrollo se focaliza, ya sea, en la delimitación del cuerpo adolorido dado en su esfera física (Körper) en atención de sus propiedades materiales, y en la eventual integración de este cuerpo dado pasivamente en la llamada estructura noético-noemática a propósito de la revelación intencional que implica el dolor. Para llevar a cabo esto, en primer lugar, se examinará brevemente el dolor a la luz de la pasividad "primigenia". En segundo lugar, se contemplará el modo a través del cual se da el cuerpo en su disposición real y su comprensión a modo de ego corporal (embodied ego) en la experimentación de dolor. En tercer lugar, considerando la constitución "primigenia" del cuerpo adolorido en un sentido amplio, se hará hincapié en su correspondencia con la intencionalidad, asunto que no hace sino corroborar que el dolor es una forma de percepción. Por último, se da paso al despliegue del nóema visto genéticamente sobre la base de la determinación del cuerpo real como objeto noemático.
\end{abstract}

Palabras clave: intencionalidad, pasividad primigenia, objeto, Husserl.

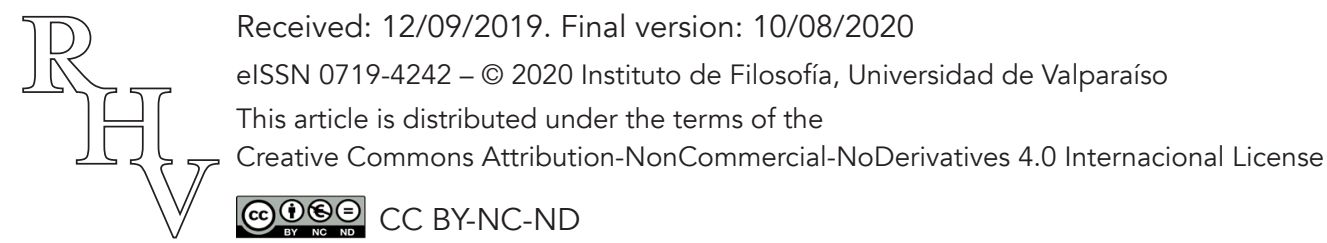


Génesis del nóema: Un análisis noemático a partir de la constitución del cuerpo adolorido

Alejandro Escudero Morales

\begin{abstract}
The objective of this work is to carry out a genetic study on the Husserlian concept of noema based in the givenness of the real body in the passive experience of pain. The development focuses, either, on the delimitation of the painful body given in its physical sphere in attention to its material properties, and in the eventual integration of this passively given body in the so-called noetic-noematic structure regarding the intentional revelation that pain implies. To do this, pain will first be briefly examined in light of "original" passivity. Secondly, the way in which the body is given in its real disposition and its understanding as a bodily ego in experiencing pain will be contemplated. Thirdly, considering the "original" constitution of the body in pain in a broad sense, emphasis will be placed on its correspondence with intentionality, a matter that only confirms that pain is a form of perception. Finally, the deployment of the genetically viewed noema is given on the basis of the determination of the real body as a noematic object.
\end{abstract}

Keywords: intentionality, original passivity, object, Husserl.

\title{
1. Introducción
}

La necesidad de estudiar el nóema encuentra razón en la importancia que detenta en el marco de la conciencia intencional pura. Teniendo presente que a lo largo de la tradición fenomenológica ha sido objeto de distintas interpretaciones, en la actualidad se hallan aproximaciones que destacan la "ampliación" de sus condiciones necesarias al punto de verlo junto con órdenes disimiles al establecido en Ideas relativas a una fenomenología pura y una filosofía fenomenológica. Libro primero: Introducción general a la fenomenología pura (en adelante Ideas I). Es el caso de la propuesta de Zahavi que es partidario de abordar el nóema junto con una interpretación más general de la filosofía de Husserl con tal de no discutirlo de forma aislada (Zahavi 2003, 60; 2017, 93) interpretación obtenida al alero de filosofías de corte existencial (Zahavi 2004, 62). Asimismo, Rabanaque promueve un estudio genético, ya sea, donde muestra el papel de las cinestesias en el nóema perceptivo exhibiendo una dimensión que lo liga a la sensibilidad primigenia (Rabanaque 2010, 197), como también, describiendo los grados de la idealidad noemática de acuerdo con los presupuestos de la fenomenología genética (Rabanaque 2003, 328-332; 2009, 73-78). De ambos autores se destacan la factibilidad de una determinación complementaria, esto es, la posibilidad de poder advertir, contenido en sus condiciones, criterios que permitan estudios junto con dimensiones de análisis que en principio no le correspondería. Esto puede ser viable una vez alcanzada, ya sea, la certeza de contemplarlo en experiencias de un orden opuesto al estático, como también, su apertura a consideraciones 
no estrictamente sujetas al camino cartesiano. En este sentido, al nóema se le abriría una disposición cuya característica principal sería dejar su territorio específico conforme se logra alcanzar espacios que por definición serían para él desconocidos.

Reconocido como parte de la conciencia en su versión intencional, las condiciones necesarias del nóema están definidas — junto con la nóesis (y su carácter ingrediente) en la disposición estática de la fenomenología-. En tal sentido, el nóema en su acepción genérica es distinguido por ser "lo intencionado en cuanto tal" de una vivencia específica. De acuerdo con esto, Husserl en virtud de la descripción eidética-noemática desarrollada en Ideas I, define el nóema desplegando los “momentos (Momente) noemáticos" entre los cuales se reconocen la $\mathrm{X}$, el sentido (ambos componen el núcleo noemático), y las tesis noemáticas. Respecto del primer momento afirma que,

Se distingue como momento noemático central: el objeto, el objeto, lo idéntico, el sujeto determinable de sus posibles predicados - la pura X en abstracción de todos los predicados-, y se distingue de estos predicados, o más exactamente, de los nóemas de los predicados. (Husserl 2013, 400)

La X no puede faltar al ser la referencia del siguiente momento, en tanto, "Todo nóema tiene un «contenido», a saber, su «sentido», y se refiere mediante él a «su» objeto" (Husserl 2013, 396). En rigor, es el sentido como "objeto en el cómo de sus determinaciones" (Husserl 2013, 401) el que se refiere al objeto, en la medida en que sea "su" objeto. Por último, las tesis logran exhibirse en el marco de la reducción puesto que,

Ellas están, en efecto, ahí, copertenecen esencialmente al fenómeno. Nosotros más bien las contemplamos; en lugar de tomar parte en ellas, las convertimos en objetos, las tomamos como partes integrantes del fenómeno, tomamos la tesis de la percepción justo como su componente. (Husserl 2013, 300)

No obstante, dada esta filiación necesaria que mantiene con la fundamentación estática, ¿Cómo estudiarlo en consonancia con un modelo distinto al estático al modo como lo realizan Zahavi y Rabanaque? Fundamentalmente, como será expuesto a lo largo del artículo, considerando la dación objetiva que sucede en la experiencia que guiará el presente trabajo, esto es, la experiencia de dolor. En este sentido, el trabajo consistirá en un estudio que vislumbre el nóema en una perspectiva ampliada y no sometida solo al ámbito estático, en particular, desde un punto de vista genético. Para llevar esto a cabo se seguirá al pie de la letra la intuición que tuvo alguna vez Derrida en El problema de la génesis en la filosofía de Husserl cuando realiza el siguiente alcance: "[...] la génesis del nóema a partir del objeto «real» acogido pasivamente no está clara en el pensamiento de Husserl (Derrida 1990, 152, traducción mía). En definitiva, se explicará cómo se da este objeto real que no es sino el cuerpo físico (Körper) con sus propiedades materiales presentado a través de esa experiencia concreta y pasiva. A fin de cuentas, esto generará la integración 
de la "pasividad primigenia (originaire)"1 de dolor en la que el objeto real se da en aquel "mundo cerrado de las estructuras noético-noemáticas" (Derrida 1990, 152, traducción mía).

\section{La pasividad del dolor}

El dolor puede ser rastreado en distintos textos de Husserl. Ya sea en Ideas relativas a una fenomenología pura y una filosofía fenomenológica. Libro segundo: Investigaciones fenomenológicas sobre la constitución (en adelante Ideas II) cuando señala que "si las mano es pellizcada, oprimida, golpeada, pinchada, etc., si es tocada por cuerpos ajenos o toca cuerpos ajenos, entonces tiene sus sensaciones de toque, de pinchadura, de dolor, etc." (Husserl 2005, 185); En Ideas I cuando se refiere a las vivencias denominadas sensuales como "las sensaciones sensuales de placer, de dolor, de comezón, etc." (Husserl 2013, 282); O en sus Lecciones de 1907 de Göttingen, donde manifiesta que "Las sensaciones cinéticas pertenecen aquí, pero también lo hacen otras sensaciones, que incluso tienen una primaria función materializadora para las cosas que aparecen, como las sensaciones del tacto y también sensaciones como el dolor y el placer, etc." (Husserl 1997, 65). Estas referencias tienen en común la imposibilidad de determinar reflexiones sobre este tema en su pensamiento. En vez de plantear específicamente cuáles son sus propiedades, para Husserl el dolor tiene una función ejemplificadora marcada por las reflexiones de orden pasivo que lleva a cabo en distintos marcos argumentativos. De hecho, como bien menciona al pasar Biceaga, "Sin preocuparse demasiado por este problema, Husserl agrega que los impulsos, los instintos y las sensaciones, como el dolor [...] pertenecen a esta esfera [pasiva]" (Biceaga 2010, 20, traducción mía). De esto se deduce que el dolor para él, en vez de ser un tema que debía ser abordado, solamente tiene un papel secundario.

Las consideraciones anteriores comparten un punto fundamental sobre el cual se divisa su condición pasiva en virtud de la naturaleza sensible que detenta. Pero, ¿Qué comprende Husserl por pasividad? En un sentido general, la pasividad es habitualmente entendida por ser un tipo de análisis fenomenológico que vislumbra entre otras cosas el modo como afecta un objeto sobre el ego (Husserl 2001, 162-242). De acuerdo con esto, la pasividad concebida en términos relativos a la afección es reconocidamente "pre-dación pasiva" (Rizo-Patrón 2012,365) respecto de aquellos objetos que "ya están allí".

Es en este orden donde se hallan diferentes determinaciones aludiendo incluso a su papel correlativo conforme a la actividad egológica. Husserl encuentra en la pasividad "[...] las leyes esenciales de una formación pasiva de síntesis siempre nuevas - que, en parte, precede a toda actividad y, en parte abarca nuevamente toda actividad-" (Husserl

\footnotetext{
${ }^{1}$ Traduzco el concepto originaire como "primigenio" en vez de "originario" porque está en consonancia con el concepto alemán ursprünglich que Husserl desarrolla al referirse a la "constitución primigenia" en Ideas II.
} 
1986, 106); vale decir, encuentra en ella "una génesis pasiva de las múltiples apercepciones, como configuraciones persistentes en una habitualidad que le es propia, las que parecen datos previos formados para el yo central, que al actualizarse afectan y motivan a actividades" (Husserl 1986, 106). Su terreno está delimitado en función de su condicionante pre-dación de datos formados que eventualmente afectarían al ego. A raíz de dicha precedencia y carácter abarcador, esta síntesis contiene esa habitualidad de los datos que alguna vez fueron conciente y que pueden ser activados. No es fortuito que las cosas sean conocidas o reconocidas por el yo considerando que la síntesis pasiva sigue operando. Es razonable constatar en ella una "historia" propia, puesto que, "[...] precisamente esa síntesis, como síntesis de esa forma, tiene su historia que se anuncia en ella misma" (Husserl 1986, 105). Así, esta historia tiene la particularidad de disponer de la cosa de tal manera que "[...] en su síntesis obviamente pasiva aparece la cosa una, con su forma, etc." (Husserl 1986, 105). Esta dilucidación "histórica" permite que "el yo, el ego, y ya desde la primera mirada, [pueda] tener la experiencia de una cosa" (Husserl 1986, 105). El ego posee continuamente la capacidad de "activar" lo pre-dado en la medida en que los objetos del horizonte lo afecten. Aun así, "Gracias a esa síntesis pasiva el yo tiene siempre un contorno de objetos" (Husserl 1986, 106). Sea el caso de un objeto conocido o por conocer, ambos se deben a la forma de esta síntesis en particular. En el caso de un objeto desconocido ocurre lo mismo puesto que es "una forma estructural de lo conocido; [ya que] tiene la forma objeto y más precisamente la forma cosa espacial, objeto cultural, utensilio, etc.” (Husserl 1986, 106).

De acuerdo con esto, pensar la pasividad del dolor solo puede estar sometido a este ámbito donde aún no hay un objeto dado para el ego. Este es el alcance que Walton realza en su comentario efectuado a propósito de la ponencia de Serrano de Haro titulada, "En los límites de la fenomenología: el análisis del dolor físico":

En los fondos de la pasividad conciente, a los que únicamente se abre paso la fenomenología genética, no se vive aún en la correlación noético-noemática; con fuerza variable, los contenidos hyléticos afectan aquí a un yo, o inciden sobre un yo, que es apenas un centro de afecciones y reacciones "instintivas", que es también por tanto un pre-yo. (Serrano de Haro 2010a, 98)

Para Walton no correspondería pensar el dolor bajo estos términos siendo que " [...] las diferencias típicas de la experiencia intencional como la dualidad intención-cumplimiento, o incluso la dualidad entre la síntesis noética y los términos noemáticos, no resultan aquí aplicables, todavía”. (Serrano de Haro 2010a, 98). En este sentido, en vez de la participación egológica caracterizada por "funcionar como constituyente, como productiva, por medio de actos específicos del yo" (Husserl 1986, 103), en la que este ego se caracteriza por la autoría que posee sobre los actos activos y sobre el cual las objetividades constituyentes son atestiguadas por el horizonte intersubjetivo, el dolor, más bien, se enmarca en un campo pre-donante, lugar de una síntesis con una determinación pre-egológica. 
Pese a que se podría descartar su presencia, según este énfasis el yo en principio "participa" en la pasividad de un modo peculiar (Husserl 2001, 631; Steinbock 1998, 139). Captado siendo la fase anterior a su presencia propiamente tal, el ego en la pasividad halla en la expresión "pre-" su sentido fundamental.

Si bien esta pasividad es acentuada en su índole pre-egológica donde no habría una dación propiamente tal, ¿a qué se refiere Derrida cuando menciona la "pasividad primigenia"? En especial, a un ámbito hylético donde habría una "intervención exterior, por un objeto que se impone" (Derrida 1990, 151) al yo puro en vista de la actualidad que eventualmente toma por esta imposición objetiva. Básicamente este aspecto actual le es "[...] conferido [al yo puro] por otra cosa que no es el mismo" (Derrida 1990, 151) provocando que se torne concreto; es decir, dicho brevemente con otras palabras, existe en esta pasividad la dación de un objeto con su debido énfasis primigenio. De esta manera, ¿Qué ocurre si esta pasividad es estudiada a la luz de la constitución primigenia que Husserl investiga en Ideas III? Y si es así, ¿En qué sentido habría que comprender la imposición de un objeto y la subsiguiente propensión concreta de la que habla Derrida? Para responder estas interrogantes se ocuparán los planteamientos efectuados por Husserl en Ideas II donde advierte este alcance primigenio y concreto en atención del tema preponderante del presente trabajo, es decir, la dación y constitución del cuerpo adolorido.

\section{Constitución del cuerpo adolorido}

El dolor que se siente en la columna después de un ejercicio mal realizado, el dolor de cabeza que invade en el trascurso de una actividad de trabajo, o el reconocido dolor de muelas, pueden ser ejemplos que en oportunidades, pese a que se tome algún medicamento para sobrellevarlos, impiden realizar las actividades diarias provocando literalmente un debilitamiento al punto de no poder soportarlos y tener que visitar a un profesional de la salud con el fin de ver las causas que los provocan. Todos estos son prototipos de esta experiencia concreta que, junto a la filosofía de Husserl, puede ser abordada fenomenológicamente. El cuerpo propio (Leib) en términos de "orientación", "órgano de voluntad", "órgano del espíritu", y "portador de las ubiestesias", se ve afectado en cada una de estas características. Quizás el de mayor protagonismo corresponde a este último definido así: "Todas las ubiestesias pertenecen a mi alma" (Husserl 2005, 189). Estas sensaciones que tienen lugar en mi cuerpo son mías en virtud de que mi cuerpo no es meramente una cosa; "[me] encuentro en él, y siento "en" él y "dentro" de él” (Husserl 2005, 185). Dado que el dolor es una sensación localizada en el cuerpo, se experimenta concediendo su ubicación en algún lugar determinado. Desde ya se puede ubicar cuando se indica un "dolor de cabeza", un "dolor de espalda", un "dolor de muela" etc., de donde se infiere el papel fundamental en el respecto sensorial. Por su parte, en tanto "órgano de la voluntad", el cuerpo se ve imposibilitado de realizar a "voluntad" sus movimientos aun cuando es definido como un yo que tiene "la capacidad ("yo puedo") para mover libremente este 
cuerpo o los órganos en que se articula, y para percibir mediante ellos un mundo externo" (Husserl 2005, 192). Al encontrarse gobernado por el dolor, el sujeto en vez de moverse libremente se encuentra merced a esta experiencia de modo que sus movimientos no pueden sino estar preso de esta situación. Asimismo, la "orientación" del cuerpo junto con la concepción de este órgano "espiritual", se encuentran dominadas por una experiencia ajena que entorpece la normalidad de la vida. Ese centro de orientación desde donde "yo tengo todas las cosas frente a mí, todas están "allí" — con excepción de una única, precisamente el cuerpo, que siempre está aquí" (Husserl 2005, 198-9) se ve condicionado por esta experiencia ingobernable, al igual que el cuerpo entendido junto con el alma, la cual no puede faltar ya que si es así "tenemos materia muerta, una cosa meramente material que ya no tiene en sí nada del hombre-yo" (Husserl 2005, 129).

No obstante, esta dimensión corporal no es la única que se ve convocada en la experiencia de dolor. Como bien afirma Husserl, no hay que olvidar que el cuerpo propio detenta necesariamente dos dimensiones, esto es:

El cuerpo (Leib), por ende, se constituye primigeniamente de manera doble: por un lado es cosa (Ding) física, materia, tiene su extensión, a la cual ingresan sus propiedades reales, la coloración, lisura, dureza, calor, y cuantas propiedades materiales similares haya; por otro lado, encuentro en él, y siento «en» él y «dentro» de él: el calor en el dorso de la mano, el frío en los pies, las sensaciones de toque en las puntas de los dedos. (Husserl 2005, 185)

Si bien el dolor está subordinado a la dimensión protagonizada por la sensación localizada o ubiestesia "perteneciente a mi alma" (Husserl 2005, 189), también debe ser comprendido en el marco corporal identificado con esas propiedades reales bajo su condicionante materialidad. Esta validez solo es revelada siguiendo el designio del "fenómeno de doble sensación" que no debe sino ser reinterpretado dada la naturaleza del cuerpo adolorido. Téngase en cuenta, por una parte, que las apariciones táctiles de la cosa mano izquierda son constituidas por "las sensaciones de movimiento indicadoras y las sensaciones táctiles representantes [...] pertenecientes a la mano derecha" (Husserl 2005, 184); y por otra parte, que la correspondiente constitución de esa mano izquierda está determinada por su devenir corporal en la cual "encuentro también en ella series de sensaciones táctiles" (Husserl 2005, 184), ocasionando que ella sienta del mismo modo que la mano derecha.

Mas, en el caso del dolor, por ejemplo, de apéndice, sucede algo singular, esto es, el apéndice aparece específicamente como cuerpo adolorido. Su aparición surge al momento de esta sensación a modo de sensación "localizada" presentada "si el cuerpo es tocado, presionado, pinchado., y se presenta ahí donde lo es y cuando lo es" (Husserl 2005, 186). A pesar que el apéndice aparece efectivamente como siendo mi cuerpo, el dolor pertinente actúa como un "agente externo" puesto que asiste de modo similar a la llegada de un intruso en un hogar. De alguna manera, su presencia es fundamentalmente una presencia distinguida por aparentar la forma de un "forastero". De todas formas, pese a actuar como

Revista de Humanidades de Valparaíso, 2020, No 15, 65-80 
un elemento desconocido, el dolor atribuido al apéndice no dejar de ser mío ya que lo padezco en mi cuerpo. Aunque actúa como un desconocido, el dolor no solo se origina en el cuerpo afectado sino que termina en él.

Conforme a una interpretación propiamente táctil, el dolor correspondiente puede ser identificado siendo aquella sensación que toca mi apéndice. Esto significa que el apéndice adolorido, concebido como sensación tocante, es comprendido en un sentido similar a las sensaciones indicadoras que tengo en mi mano derecha cuando es tocada la cosa mano izquierda. Empero no hay que dejar pasar una diferencia de acuerdo con el planteamiento del propio Husserl cuando se vincula esta sensación de dolor y la sensación táctil. Téngase en cuenta si la sensación de toque,

[...] sucede por medio de otra parte del cuerpo, entonces tenemos lo mismo duplicado en ambas partes del cuerpo, porque cada una es para la otra precisamente cosa externa que toca, que produce efectos, y cada una es a la vez cuerpo. (Husserl 2005, 185)

La diferencia se ajusta a una razón fundamental: el apéndice adolorido no solo puede ser concebido como sensación tocante sino que a la vez se revela como lo tocado. Esto significa que la sensación de dolor toca el cuerpo que no es sino el mismo cuerpo tocado. No se condice con el principio táctil de Husserl cuando menciona que "En el ámbito táctil tenemos el objeto externo que se constituye táctilmente y un segundo objeto cuerpo, que también se constituye táctilmente, por ejemplo, el dedo que palpa" (Husserl 2005, 187), básicamente por dos razones: sea porque el objeto que se constituye táctilmente por el dolor es un objeto interno y porque el objeto cuerpo correspondiente que se constituye por el tacto es ese mismo objeto interno. En principio le compete la "aprehensión doble" considerada "la misma sensación de tacto aprehendida como nota del objeto «externo» y aprehendida como sensación del objeto-cuerpo" (Husserl 2005, 187), aunque en un sentido distinto en vistas de la naturaleza del objeto aludido. La misma sensación de dolor es aprehendida como nota del apéndice en tanto objeto interno y, como sensación del cuerpo. En este sentido, el apéndice adolorido no sería sino aprehendido como objeto interno y a su vez como cuerpo propio.

Ahora bien, el punto preponderante a especificar está contenido en estas reflexiones de la siguiente manera: si se considera el apéndice adolorido junto con la constitución doble del cuerpo, vale decir, con la necesidad de principio que lo determina como cuerpo (Körper) en su calidad de cosa física ligada a propiedades reales y como cuerpo propio en atención de su condicionante carácter de portador de sensaciones localizadas, en seguida se exhibe un aspecto indispensable que no puede ser eludido, a saber: el cuerpo físico aparece a continuación de la determinación del cuerpo adolorido de momento que se encuentra ciertamente condicionada por esta necesidad de principio conforme al cuerpo propio; dicho de otra manera, el apéndice en su índole material, con su extensión, junto 
con su determinada coloración, lisura, dureza, y cuantas propiedades materiales posea, se desvela, entre otras razones, gracias a la necesaria constitución doble de este cuerpo adolorido.

Por este motivo la dación material del apéndice adolorido es engorrosa. En vez de ser el apéndice real presentado directamente como lo es la dación material de la mano izquierda para la mano derecha experimentante, la dación de este objeto interior real es presentado por medio del dolor, vale decir, es entregado a propósito de otra experiencia. En estricto rigor, la única manera de tener noticias de este objeto real para quien padece dolor es a través de esta constitución primigenia. Por consiguiente, dichas propiedades materiales del apéndice no se dan como se da la cosa mano izquierda por "las sensaciones táctiles representantes [...] pertenecientes a la mano derecha" (Husserl 2005, 184), sino que su dación, más bien, se rige por una dación "indirecta". Cabalmente, esta constitución se halla supeditada al dolor visto como experiencia concreta, es decir, vivida por aquel cuerpo adolorido, por ese yo competente, pero por sobre todo, a causa de que el apéndice real es un objeto interno.

Como sea, noticias de esta cosa (Ding) hay en vista de esta experiencia privilegiada que, aunque desagradable, revela un objeto al que se accede desde que surge el dolor respectivo. En realidad, su presentación no deja de ser compleja, pues, se presenta por medio de una experiencia que se relaciona con objetos internos y no externos. Pero, ¿qué es lo que se da en última instancia en la experiencia de dolor? Si es considerado el cuerpo junto con el hilo conductor relativo al enfoque egológico, lo dado en definitiva es el ego entendido a modo de "[...] ego corporal (embodied ego)" (Drummond 2007, 63). En efecto, el ego al intervenir de un modo concreto y no mediante un acto activo, vale decir, haciendo su presencia de modo circunstancial e inesperadamente, toma la forma de este cuerpo adolorido. Aun así, si se siguen los lineamientos anteriores, donde se atiende la necesidad de principio que establece la delimitación dual del cuerpo, es notificada una concepción que incide en este dominio. En última instancia lo dado no es esa dimensión egológica, sino más bien, aquella determinada por el cuerpo físico-real que en tanto tal es vislumbrada a propósito de este análisis. El ego en cuestión no es sino un ego real, a consecuencia de que el ego toma la forma de esta cosa, del apéndice con sus propiedades reales, en función de la revelación que se dispone en el dolor, en particular, del apéndice adolorido.

\section{El dolor como forma de percibir}

En el fondo, la intervención exterior por un objeto que se impone al yo puro (Derrida $1990,151)$ incluye una imposición concreta en el que el objeto pertinente es un objeto interno, siendo dicha intervención exterior condicionada internamente. Como bien fue señalado con anterioridad, la naturaleza propia que detenta el cuerpo adolorido contiene este carácter donde hay una intervención exterior a manera de un desconocido, por un 
forastero que más bien no dejo de ser yo en razón de que es mi sensación localizada. Lo relevante se halla en el hecho que ese objeto impuesto es precisamente el yo en su disposición real. En vez de ser conferido al yo puro su actualidad, como señala Derrida, "por otra cosa que no es el mismo" provocando que se torne concreto (Derrida 1990, 151), esta actualidad es conferida por el yo mismo, puesto que él es esta intervención.

En este punto es necesario revisar el alcance realizado por el propio Derrida desde otro ángulo en función del estudio genético en torno al nóema: "En ese mundo cerrado de las estructuras noético-noemáticas y de la vivencia intencional «irreal», ¿podrá integrarse sin misterio la pasividad primigenia en la que el objeto real se da «él mismo»? (Derrida 1990, 152 , traducción mía). Si, en la medida en que la pasividad primigenia en cuestión sea el dolor concebido precisamente de modo primigenio y el objeto real dado en ella sea la corporalidad egológica en su disposición material. Empero, la integración en la estructura noético-noemática de este cuerpo adolorido no solo es abogada por esta dación sino que por la noción que predomina en la exposición que ha sido realizada hasta acá, esto es, la "constitución primigenia".

La focalización en esta constitución implica cuestiones que no son sencillas aun cuando es fundamental en esa integración. Este alcance se halla motivado por el sentido que posee la constitución del dolor siguiendo el prototipo táctil, tal como lo delimita Geniusas (2014). No deja de llamar la atención que la constitución en general es "ambigua, fragmentaria, parcial y fuente de nuevos problemas" (San Martin 1986, 245). Advirtiendo esto, Adrián en la introducción de La idea de la fenomenología pregunta, "¿Qué cabe, pues, entender exactamente por «constitución»? [Lo cual replica] Dicho con brevedad, la constitución es un proceso que permite la manifestación y significación" (Husserl 2011, 35). En tal sentido, la constitución primigenia competente del caso, por ejemplo, de un dolor de muelas es señalada una vez advertida la "manifestación" de una pieza particular y no la contigua. En su calidad primigenia, esta constitución compete a un estadio primario de dicho proceso, debido a que, tomando en estricto rigor esta condición, ella es una faceta primitiva respecto del eventual desarrollo del proceso constitutivo. En efecto, para Husserl "Primigeniamente no quiere decir aquí nada temporal-causal; se trata de un grupo primario de objetos que se constituyen de modo directamente intuitivo" (Husserl 2005, 188). En este sentido, este carácter primigenio está sustentado en aquellas localizaciones de las ubiestesias del cuerpo experimentante. En síntesis, señala que "El cuerpo sólo puede constituirse primigeniamente como tal en la tactualidad y todo lo que se localiza con las sensaciones táctiles, como calor, frío, dolor, y similares" (Husserl 2005, 190).

En definitiva, ¿Cómo se integra el dolor primigenio donde se da el cuerpo real en la llamada estructura noético-noemática? Principalmente obedeciendo a un sentido ampliado de la constitución primigenia asemejada a la constitución, como dice Husserl en la III Meditación Cartesiana, "[...] de un objeto intencional en general” (Husserl 1986, 76). 
Esta sugerencia trae consigo un asunto no menor a causa de la correspondencia fundamental que detenta la constitución en la fundamentación fenomenológica con relación a la intencionalidad. Sobre este aspecto Husserl afirma que,

[...] el objeto intencional que está del lado del cogitatum es el que desempeña el papel del hilo conductor para el descubrimiento de los múltiples tipos de cogitationes que, en una síntesis posible, llevan en sí conciencialmente ese objeto como mentado en su identidad. (Husserl 1986, 68)

En virtud del "punto de partida [que] es el objeto dado en cada caso de modo directo" (Husserl 1986, 68) se evidencian los distintos modos de conciencia posibles, específicamente, en "las series de tipos particulares noético-noemáticos netamente diferenciados" (Husserl 1986, 68), referente a ese objeto idéntico. Hay una especie de correlación en la medida en que "todos estos tipos se particularizan, a su vez, en su total composición noético-noemática, tan pronto como especificamos la generalidad del objeto intencional hasta ahora mantenida vacía" (Husserl 1986, 68). En este sentido, una mirada universal-formal expone especificaciones ontológicas-materiales que reflejan las regiones reales, vale decir, cosa espacial, ser animal, etc. (junto con las especificaciones lógico-formales) (Husserl 1986, 68-69). Para Husserl "la tarea de la teoría trascendental consiste justamente en explicitar sistemáticamente esos tipos estructurales" (Husserl 1986, 69), vale decir, a la luz del objeto como "hilo conductor", se explicitan los tipos estructurales de cada vivencia posible en su estructura noético-noemática. Ahora bien,

[...] cuando esta teoría toma como hilo conductor una universalidad objetiva, se llama teoría de la constitución trascendental del objeto en general, en cuanto objeto de la correspondiente forma o categoría o, en el punto más alto, de la región en cuestión. (Husserl 1986, 69)

De esta manera, son dos tipos de tareas que certifican dos ámbitos de estudio que, en tanto tal, son señaladas en virtud del objeto intencional a modo de hilo conductor. La necesaria relación entre la constitución y la intencionalidad es subrayada aún más cuando las diferentes teorías de los tipos estructurales, tales como, la percepción, el juicio, etc., se fusionan para "colaborar funcionalmente en la teoría constitutiva formal y universal de un objeto en general, o bien de un horizonte abierto de posibles objetos en general en cuanto objetos de una conciencia posible" (Husserl 1986, 70).

A raíz de esta concepción ampliada de la constitución primigenia el dolor puede ser distinguido conforme a una forma de percepción de acuerdo con la correspondencia entre aquella constitución con la intencionalidad. Aunque en principio parezca un asunto profundamente discutible a causa de que el estudio sobre el dolor se sitúa en la pasividad donde "[...] las diferencias típicas de la experiencia intencional como la dualidad intención-cumplimiento, o incluso la dualidad entre la síntesis noética y los términos noemáticos, no resultan aquí aplicables, todavía". (Serrano de Haro 2010a, 98), gracias a 
la ampliación del sentido de esta constitución es factible reexaminar y, más importante, corroborar la disposición intencional del dolor. Desde luego que la posición sigue una tendencia propia respecto de las indicaciones temáticas que realiza, por ejemplo, Sartre cuando afirma que "[...] el dolor está totalmente desprovisto de intencionalidad" (Sartre 2008, 459). Para éste filósofo esta experiencia no tiene un correlato objetivo. La finalidad "de una conciencia dolorosa es proyecto hacia una conciencia ulterior, que sería vacía de todo dolor [...]" (Sartre 2008, 460). Asimismo, pese a que su postura no es propiamente fenomenológica, Scarry en su libro The body in pain comparte con Sartre esa condición no objetiva, ya que el dolor en tanto "estado psíquico, somático y perceptivo es el único que no tiene objeto". Recalca su postura señalando lo siguiente:

Aunque la capacidad de experimentar dolor físico es un hecho primario en el ser humano como lo son la capacidad de oír, tocar, desear, temer, tener hambre, ella difiere de estos hechos, y de cualquier otro hecho corporal o psíquico, por no tener un objeto en el mundo externo. Escuchar y tocar lo son respecto de objetos que están fuera de los límites del cuerpo, igual que el deseo es deseo de $\mathrm{x}$, el temor es temor de $\mathrm{y}$, el hambre es hambre de $\mathrm{z}$. Pero el dolor no es "de" o "por" nada - es él mismo a solas. Esta falta de objeto, su completa ausencia de contenido referencial, se halla cerca de impedir que el dolor pueda ser llevado al lenguaje: como falto de objeto, no puede fácilmente ser objetivado de ninguna manera, sea ella material o verbal. (Scarry 1985, 161-162, traducción mía)

Sin embargo, a diferencia de ambos planteamientos, el punto sostenido aquí es precisamente esta incapacidad que detenta la conciencia de abandonar un órgano en vistas de su dolor. Pensarlo desprovisto de intencionalidad y de una objetividad no halla razón una vez esclarecido que el objeto en cuestión no es un objeto externo sino que uno interno. Es también, de alguna manera, el acento objetivo que confiere Serrano de Haro cuando distingue la naturaleza irruptiva del dolor frente a las sensaciones en general del siguiente modo,

El primer contraste entre las sensaciones y el dolor se puede resumir de la siguiente manera: en la básica teoría husserliana, los datos sensibles son parte de las experiencias vividas, pero no son el objeto intencional primario ni son parte de este objeto. Para convertirse en objetos percibidos, las sensaciones tienen que ser objetivadas mediante un nuevo acto reflexivo. En claro contraste, las noticias dolorosas no nos alcanzan por una vía reflexiva, sino más bien por una apariencia irruptiva. (Serrano de Haro 2010, 391, traducción mía)

Entre uno y otro realce, el apartado problemático dice relación con la distinción entre la sensibilidad sin objeto y aquella que si lo comprende como es el caso del dolor. De hecho, tal como fue visto anteriormente, dicha objetivación material acontece cuando es revelado a raíz de esa experiencia, en particular, una vez identificado la corporalidad egológica en su disposición real. De esta manera, su índole intencional queda sujeta a esta determinación objetiva. 
Hay que admitir que ante la ignorancia es difícil conocer el lugar que tienen ciertos órganos. Empero, a partir del dolor que comienza en cierto lugar del cuerpo, en este caso específico, en la parte inferior derecha del abdomen, ese conocimiento podría cumplirse. De una u otra manera, es admisible afirmar que los órganos del cuerpo logran ser conocidos desde que comienzan a doler, conforme se percibe el apéndice que se ubica en esa parte del abdomen. En este sentido, lo percibido es aquello que era previamente desconocido para aquel que ignoraba su ubicación. De acuerdo con esto, soy conciente de este objeto que ignoraba pero que conocí a raíz de su dación o manifestación. Basta afirmar que soy conciente de un objeto al igual que soy conciente de un árbol que está delante de mí. Pero el objeto intencional en cuestión soy yo y no, según el acto perceptivo, un objeto percibido en el horizonte externo. En contraposición de la lectura intencional autoconsciente que propone Geniusas, es decir, cuando sigue el modelo de los tres grados estructurales de la conciencia de Sartre (1968, 13-32), distinguiendo "(1) el dolor experimentado prerreflexivamente; (2) tematizado como un objeto de reflexión personal y afectivo; (3) [y] experimentado una vez internalizada la perspectiva del Otro sobre mi cuerpo" (Geniusas 2017, 337), acá es adoptada literalmente la noción intencional de Ideas I, eso sí, enfatizando que soy conciente de mi cuerpo con una conciencia "cualificada", es decir, con una forma especial de percibir.

\section{Momentos del nóema}

Llegado este punto cabe advertir que la manera en la que la pasividad primigenia se integra en la estructura noético-noemática se encuentra motivada si el dolor primigenio es concebido en términos de percepción, vale decir, como una forma de percepción. Sobre la base de este postulado, las noticias del objeto real dado «él mismo» pasivamente están propiciadas por esta sensación que no debe sino ser entendida como percepción. En este sentido, se recalca el enfoque intencional que no hace sino corroborarlo perceptivamente habida cuenta de la "conciencia de" un objeto interior tal como es el apéndice. Al amparo de esta postura ¿Cómo habría que comprender el nóema? ¿Cómo se explica su génesis a partir del cuerpo real acogido pasivamente? La determinación noemática acorde a la experiencia de dolor comienza al garantizarse este cuerpo real a modo de correlato objetivo análogo al nóema de la percepción en atención específica del momento denominado "objeto noemático". En efecto, el dolor al percibir el apéndice lo certifica como el "[...] necesario centro, el punto de unidad, la pura X determinable" (Husserl 2013, 400). A tal efecto, el apéndice es el "momento noemático central: el objeto, el objeto, lo idéntico, el sujeto determinable de sus posibles predicados - la pura X en abstracción de todos los predicados" (Husserl 2013, 400). En lugar de la aseveración de Serrano de Haro, esto es, "no hay una división interna entre lo hylético, lo noético y lo noemático" (Serrano de Haro 2010, 387), de acuerdo con el estudio realizado hasta acá, se destaca que no hay una división entre el apéndice real, el ego y la X noemática. A decir verdad, cada una de estas instancias son lo "mismo" de conformidad con la corporalidad egológica dispuesta

Revista de Humanidades de Valparaíso, 2020, No 15, 65-80 
como una cosa real que, en el marco noemático, no es sino la $\mathrm{X}$, es decir, el apéndice reducido. Por lo tanto, ¿Cómo habría que comprender los demás momentos noemáticos? Respecto del sentido, como momento que el nóema contiene y definido genéricamente en cuanto "Todo nóema tiene un «contenido», a saber, su «sentido», y se refiere mediante él a «su» objeto" (Husserl 2013, 396), se encuentra asegurado desde la confirmación del correlato corporal, ocasionando un "sentido" respectivo por medio del cual se refiere al apéndice. Aunque sea paradójico, debido a que habitualmente se advierte que el dolor es una experiencia "sin sentido", con este planteamiento se abre un argumento sobre este asunto que alcanza dicha determinación en su calidad de momento noemático. Respecto de la tesis noemática correspondiente, definida como los caracteres que hay en lo percibido, lo fantaseado, etc., es decir, "[...] en el sentido perceptivo, en el sentido fantasivo, en el sentido recordativo - como algo inseparable y como algo necesariamente inherente en correlación con las respectivas especies de vivencias noéticas" (Husserl 2013, 302), sucede que está caracterizada como "realidad en persona" (Husserl 2013, 302). Al igual que la percepción, al dolor le "[...] corresponde como correlato noemático en el «objeto» que aparece el carácter de ser de lo «real»" (Husserl 2013, 333), puesto que es el apéndice el objeto real que aparece. Según esto, la certeza real respectiva impide posiciones que comprendan la conciencia bilateralmente, de duda, de sospecha, etc., básicamente porque es la única tesis que puede gobernar esta experiencia.

\section{Conclusión}

La exposición propuesta en el presente artículo demostró la factibilidad de constatar el nóema junto con dimensiones de análisis sobre los que Husserl no se detuvo cuando se trataba de examinar este concepto. Quedó de manifiesto un modo de dación objetiva que no es necesariamente de un orden activo, asunto que implicó el examen noemático desde una perspectiva genética. Para desarrollar esta posición el artículo tuvo que seguir al pie de la letra el hilo conductor delimitado por la intuición derridiana en la cual manifiesta que "la génesis del nóema a partir del objeto «real» acogido pasivamente no está clara en el pensamiento de Husserl”. En primer lugar, se comenzó por la identificación del dolor como pasividad primigenia, faceta que es en la práctica investigada por Husserl en Ideas II a propósito de la constitución corporal. En segundo lugar, se procedió a la exploración pasiva siguiendo el prototipo de esta sensación de dolor, la cual puso de manifiesto las dos dimensiones del cuerpo propio, esto es, como sensación localizada en cuanto siento "en él" y como cosa real. Se indicó que este cuerpo aparece de momento que comienza el dolor, revelando también que, en última instancia, la disposición real se da con necesidad de modo indirecto. En tercer lugar, considerando este cuerpo de modo egológico, es decir, como ego corporal (embodied ego) en su esfera real, se hizo hincapié en el concepto que abogaba esta dación específica, esto es, la constitución primigenia. Tomada en un sentido amplio, la constitución se dispuso de modo similar a aquella que Husserl elabora junto con la intencionalidad en la fundamentación de su filosofía en las Meditaciones, 
originando la sugerente posición que señala que el dolor es una forma de percepción, determinación que se corrobora enseguida al ser el dolor conciente del objeto interno conocido por apéndice. En cuarto y último lugar, la génesis del nóema se determinó siguiendo particularmente la X noemática y los sucesivos momentos del nóema, vale decir, el sentido y la tesis noemática.

En este escenario el nóema dejo, como diría Zahavi, su "aislamiento" para ser observado en otros territorios en función de esta particular versión ampliada. Pese a la dificultad de la explicación, en gran medida por la terminología husserliana, la obtención del objetivo logro su finalidad tras la dación de la corporalidad egológica real. De hecho, la única manera de tener noticias del apéndice en esa disposición es a través de la constitución primigenia del dolor. Así, queda garantizada la correlación objetiva permitiendo, entre otras cosas, la constatación de "las series de tipos particulares noético-noemáticos" (Husserl 1986, 68) de esta forma de percepción.

En consecuencia, frente a los planteamientos de Sartre, Walton y así también Scarry, pero en línea con las aseveraciones impartidas por Serrano de Haro y Geniusas, la experiencia de dolor si puede ser evaluada junto con criterios intencionales. Al encontrar su correlato objetivo dado pasivamente es viable una descripción objetiva al modo en que Husserl describe el "árbol que se encuentra delante" (Husserl 2013, 295). Queda la tarea de delimitar otras experiencias reconocidamente pasivas con tal de advertir si existe en ellas daciones objetivas.

\section{Referencias bibliográficas}

Biceaga, Víctor (2010). The concept of passivity in Husserl's phenomenology. New York: Springer.

Derrida, Jacques (1990). Le problème de la genèse dans la philosophie de Husserl. Paris: Presses Univenitaires de France.

Drummond, John (2007). Historical Dictionary of Husserl's Philosophy. Lanham, Md.: The Scarecrow Press.

Geniusas, Saulius (2014). The Subject of Pain: Husserl's Discovery of the Lived-Body. Research in Phenomenology, 44: 384-404. doi: https://doi.org/10.1163/15691640-12341294

Geniusas, Saulius (2017). On Pain, Its Stratification, and Its Alleged Indefinability. Gestalt Theory, 39(2/3): 331-348. doi: https://doi.org/10.1515/gth-2017-0023

Husserl, Edmund (1986). Meditaciones Cartesianas. Madrid: Editorial Tecnos.

Husserl, Edmund(1997). Thing and Space. Lectures of 1907. Dordrecht: Springer Science+Business Media. doi: https://doi.org/10.1007/978-94-015-8869-0

Husserl, Edmund (2001). Analyses Concerning Passive and Active Synthesis. Netherlands: Kluwer Academic Publishers. 
Husserl, Edmund (2005). Ideas relativas a una fenomenología pura y una filosofia fenomenológica. Libro segundo: Investigaciones fenomenológicas sobre la constitución. México: Fondo de Cultura Económica.

Husserl, Edmund (2011). La idea de la fenomenología. España: Herder Editorial.

Husserl, Edmund (2013). Ideas relativas a una fenomenología pura y una filosofía fenomenológica. Libro primero: Introducción general a la fenomenología pura. México: Fondo de Cultura Económica.

Rabanaque, Luis (2003). Niveles y estratos noemáticos y la idealidad del sentido. Escritos de Filosofia, 43: 321-334.

Rabanaque, Luis (2009). Cuestiones en torno al nóema. En Roberto Walton(ed.), La Fenomenología, sus orígenes y desarrollo y situación actual, pp. 39-78. Argentina: Universidad Católica de Argentina.

Rabanaque, Luis (2010). Cuerpo, cinestesia, nóema. En André de Macedo, Rosemary Rizo Patrón, y Antonio Zirión (eds.), Phenomenology 2010, Vol. 2: Selected Essays from Latin America: Traversing Multifarious Dimensions of Worldly Phenomenology, pp. 184-199. Bucarest: Zeta Books.

Rizo-Patrón, Rosemary (2012). Husserl, lector de Kant. Apuntes sobre la razón y sus límites. Areté, 24(2): 351-383.

San Martin, Javier (1986). La estructura del método fenomenológico. Madrid: UNED.

Sartre, Jean Paul (1968). La trascendencia del ego. Argentina: Ediciones Calden.

Sartre, Jean Paul (2008). El ser y la nada. Buenos Aires: Editorial Losada.

Scarry, Elaine (1985). The body in pain. New York: Oxford University Press.

Serrano de Haro, Agustin (2010). Is pain an intentional experience? En Ion Copoeru, Pavlos Kontos y Agustín Serrano de Haro (eds.), Phenomenology Volume 3: Selected Essays from the Euro-Mediterranean Area. The Horizons of Freedom, pp.386-395. Bucharest: Zeta Books.

Serrano de Haro, Agustin (2010a). En los límites de la fenomenología: el análisis del dolor físico. En Anibal Fornari y Patricio Perkins (eds.), Tiempo y acontecimiento, pp. 87-99. Buenos Aires: Editorial Biblos.

Steinbock, Anthony (1998). Husserl's static and genetic phenomenology: Translator's introduction to two essays. Continental Philosophy Review, 31: 127-134.

Zahavi, Dan (2003). Husserl's phenomenology. California: Stanford University Press.

Zahavi, Dan (2004). Husserl's noema and the internalism-externalism debate. Inquiry, 47(1): 4266. doi: https://doi.org/10.1080/00201740310004404

Zahavi, Dan (2017). Husserl's Legacy. United Kingdom: Oxford University Press. 